\title{
SALVARSAN IN SYPHILIS.
}

\section{Benario, J. (Frankfurt-a-M.).-The Frequency, Causation and Thera- peutics of Neuro recurrence after Treatment by Salvarsan a Statistical Inquiry. "Münch. med. Wochens.," No. 14, April 4, 1911.}

In this interesting paper the problem of neuro-recurrence (neurorezilive) in the form of affections of certain cratial nerves occurring in the course of acquired syphilis and its bearing upon the use of " 606 " is fully discussed. Besilles being of great general interest, the question is important from the otologist's point of view, as the eighth (anditory) nerve is most frequently the seat of the lesion. Dr. Benario has collected particulars of 126 cases of neuro-recurrence from 14,000 cases of syphilis treated by " $606, "$ and his statistics show that 118 of these occurred in the primary or secondary period, but particularly in the early secondary period. Neuro-recurrence may, therefore, be regarded ats a complication of the early stages of syphilis. The cranial nerves affected were the second to the eighth, the latter being the most frequently involved (43 per cent.), the optic nerve coming second with 26 per cent., and the facial third with over 15 per cent., the other four being much less frequently implicated. The affection was more often milateral, and either isolated or in combination with an involvement of one or more of the other six nerves. In the fifty-one asses in which the eighth nerve was implicated, the cochlea alone was involved twenty-nine times, the vestibular organ five times (thrice unilaterally), and hoth cochlea and vestibule seventeen times. In a footnote attention is drawn to Rothig's work upon the toxic effect of arsacetin upon the cranial nerves, in which it is shown that when the anditory nerve is affected, it is only in its vestibular portion and always on both sides.

In 96 per cent. of the ases the neuro-recurrence occurred within four months of the silvarsan injection, the second month being responsible for the largest number (40 per cent.). The author thinks the frequency of neuro-recurrence following treatment by salvarsam is more apparent than real, as owing to the closer study and observation of cases treated by this method such nervous manifestations are less likely to escape notice. Also the technique and dosage in the ammistration of a remedy which is new must, in many instances, be uncertain ind inalequate. The important question as to whether these affections of (ramial nerves are toxic (arsenical) in origin, or the result of a definite syphilitic process, is discussed very fully. Dr. Benario agrees with Ehrlich in attributing the neuro-recurrence to the latter and not to any neuro-tropic ation of the drug for the following reasons: (1) The long interval between the injection of the drug and the occurrence of the nervous manifestations. (2) The character of the manifestations : these are more of an irritative or inflammatory nature as compared with the atrophic changes seen after other arsenical preparations (arsacetin). (3) The affection practically always occurs during a definite period of syphilis (early). (4) Such nervous phenomenat have not been observel to fellow the use of " 606 " in non-syphilitic diseases. (5) The beneficial effects upon the neuro-recurrence of mercury, or a further injection of "606." (6) The recurrence has in a very large proportion followed treatment by small (inarlequate) doses of "606." (7) It has been shown that similar manifestations have followel treatment by mercury.

\footnotetext{
1 Benario in Mïnch. med. Wochens., No. 1, 1911.
} 
The explanation offered by Ehrlich and supported by Benario in this paper of the occurrence of neuro-recurrence is based upon the assumption that the treatment has not been sufficiently effective, and that isolated clumps of spirochetx, situated in the sheaths of the cranial nerves, have escaped the action of the drug, and have set up a strictly local lesion (perineuritis) without causing a general toxæmia, thus explaining the frequency in such cases of a negative $W$ assermamn reaction. As the result of this statistical inquiry, Dr. Benario has been able to bring forward certain important facts bearing upon the prevention and treatment of such recurrences: (1) The early secondary stage is the dangerous period. (2) Cases where the primary lesion is extra-genital, especially the type known as chancres cephaliques, are more hiable to neuro-recurrence. (3) Cases where the cutaneous eruption is of the papular variety are also more prone to such complications. (4) Healache, vertigo, timnitus and disturbances of vision are important prodromal symptoms. Bearing these facts in mind Dr. Benario urges (1) that treatment, especially in the early secondary stage, shouk be thorough and energetic; (2) that " 606 " should, when possible, taking contraindications into consideration, be administered by the intra-venous and not by the subcutaneous or intra-muscular method; (3) that the dose should not be too small, and should be followed in three or four weeks by a second injection; (4) that during the intervening period mercury should be pushed. Further, the patient should be warned to return at once on the appearance of the prodromal symptoms. The treatment of the neuro-recurrence itself consists in the energetic use of salvarsan or mereury, and the results are generally good unless, owing to molue delay, permanent degenerative changes in the nerves have occurred. Dr. Benario's paper is of special interest to otologists as indicating the much greater frequency than has hitherto been supposed of early syphilitic disease of the anditory nerve or labyrinth. Mention is made, in a short supplement to two articles bearing on this subject by Meger and Frey, which appeared in the Wien. klin. Workens., No. 11, 1911. In a post-scriptum twelve alditional cases of neuro-recurrence are briefly reported; in three the optic nerve was affected, and in nine the anditory nerve (vestibular and cochlear branches five times, vestibule alone twice, and cochlea alone twice).

$J$. Stoddait Barr.

\section{Desneux and Dujardin (Brassels). Neuro-recurrence after the Treat- ment of Syphilis with Salvarsan. "Münch. med. Wochens." No 2:3, June 6, 1911.}

The authors pullish particulars of six cases of neuro-recurrence out of 350 cases of syphilis treated with " 606 ." In two of the six there was implication of the aulitory nerve along with facial paralysis. 'The authors conclusions agree most strikingly with those of Benario, and therefore need not be repeated. They believe that neuro-recurrence is entirely a syphilitic manifestation, due to localised meningitis, and that the cause is to he fomm in an insufficient lose of " 606 " defectively administered. I'hey recommend in all primary and secondary catses the intravenous injection altogether of from 15 to $3 \mathrm{gr}$. of Salvarsan. In a short supplement the authors briefly describe a seventh case, following the alministration of " 606 ," of newro-recurrence, in which the cochlear and vestibular branches of the right anditory nerve were implicated. 


\section{Gander, Prof. H., and Guggenheim, H. Aural Complications arising during the 'Treatment of Syphilis by Organic Arsenical Products. \\ “Lit Presse Médicale," June 17, 1911.}

In this article the relative toxicity of the various arsenical compounds is discussed, especially with reference to their incidence on the eighth nerve. The writers remark that the neuro-toxic effects of these agents, recently alopted in the treatment of syphilis, varies considerably. No ot itic trouble has arisen from the administration of cacodylate or methylarsenite of sodium, even in very large doses Fhrlich's experimental investigations go to show that the toxicity of atoxyl, arseno-phenylglycine and arsacetine for the cramal nerves is considerable, whilst that of silvarsan is almost nil: white mice injected with the latter suffered no toxic effects, but injection of the former compounds indnced disturbance of orientation attended by movements resembling those of Japanese dancing-mice. 'l'wo cases of aural affection attending the use of "606," observed by M. André Castex, are quoted:

(1) 'Three injections were administered to a man, aged thirty-three, at intervals of two months. 'Ten days following the third administration he complained of pains in the head and both ears, especially violent in the right, from which there was a slight discharge of blood. Examination revealed complete deafness of the right ear and partial of the left. The right membrana tympani was congested and ecchymosed, the left was slightly reddened. Both labyrinths were inflamed.

(2) In the case of a tertiary syphilitic suffering from otitic sclerosis of long standing, the deafness rapidly increased after injection of " 606 ," and violent timnitus set in at the same time. Benario, in some recent stat istics, found that of 126 cases of nerve-lesion arising during treatment ly salvarsan, the auditory nerve was involved in fifty-seven. Finger, Rille, Beck, Urbantschitsch, Levy, Herzfeld and others have had a somewhat similar experience. The lesions usually appear during the first four months succeding the injection, sometimes very early, but especially two months afterwards. The auditory nerve is more freguently inflamed, the cochlear branch alone being involved, but the vestibular nerve may also be affected and sometimes by itself. The labyrinth trouble may or mily not be accompanied by inflammation of the middle ear. Clinically there is milateral or bilateral deafness with timnitus. Rimne is positive; anditory acuity is much impaired. Perception for the watch and arometer is lessened or even abolished. The upper tone-limit is lowered. Vertigo may be present, indicating the participation of the restibular nerve in the pathological process; in cases of isolated neuritis of this nerve there are marked vertigo, disordered equilibration and nystagmus, with normal hearing. The prognosis is favourable, most aises recover spontaneously, though not always completely, in from several weeks to montlis.

Three cases of aural complication during treatment by hectine are also recorded. II. Clayton Fox.

Avellis, Georg (Frankfurt-a-M.).-Salvarsan in Laryngology. "'Zeitsch. f. Laryugol.," Bd. iii, Heft 5.

The writer has had no trouble with his cases of intra-muscular injeetion of " 606 "; he injects deeply into the shoulder muscles. With regard to intra-venous injection, he thinks it best to expose the vein by incision. Catse 1: Primary sore on tonsil healed in ten days. Case 2: Letukoplakia and rupia healed in three weeks this case had resisted iodide and mercury for six months. Case 3 : Failure in a case of small-cell sarcoma 
of tonsil and palate. Case 4: Failure in case of tabetic paralysis of posticus. Friedländer and Mickley report good results in secondary syphilitic lesions of mucous membranes. Disease of the optic and also of the auditory nerve has been observed after " 606 ." Ehrlich believes that these troubles are due to the fact that nerves are badly supplied with blood, so that the spirochretes cannot be acted on by the drug.

J. S. Fraser.

Safranek, J. (Budapest).-Arsenobenzol in Syphilitic Diseases of the Upper Air-passages. "Zeitsch. f. Laryngol.," Bd. iii, Heft, 5.

Most arsenical preparations are not only tosic to the spirochete (parasitotropic) but also to the host (organotropic). Salvarsan is parasitotropic without being organotropic. The drug acts well, not only in cases of primary sore, mucous patches and condylomata, in which the organisms are present in large numbers, but also in cases of tumourformation and ulceration in which they are absent or seanty ; the remedy also is very beneficial if given to the mother before the birth of a childprobably on account of the liberation of endotoxin. Occasionally it fails to act, while in other cases there is a return of the disease. The "Wassermann reaction may remain positive after the drug has been given.

Safranek reports on twenty-five cases: (1) Tertiary ulcer of septum nasi, intra-muscular injection; cure in seven days. (2) Gummatous abscess of nasal bone, ozæna; incision of abscess, subcutaneous injection of " 606," high temperature, cure in ten days. (3) Ozæna, ulcer of nasopharynx, epiglottis and cords swollen and red; intrd-venous injection, burning pain in neck and ear, cure in twelve days. (4) Papular eruption in pharynx and mouth; subcutaneous injection, marked local reaction, cure in five days (seven similar cases were successfully treated). (5) Ulceration of tonsils and fauces (four cases); cure in four or five days after injection. (6) Erythematous affection of pharynx and larynx ; also reacted promptly to "606." (7) Tertiary disease of the pharynx (five patients); four of these were cured, but in one the injection did no good. (8) In one case of combined tuberculosis and syphilis of the larynx the result was fairly good. Salvarsan has a favourable action in cases of syphilitic ozæna. As a rule, there is a marked local reaction twenty-four hours after the injection in addition to the general reaction; the patient complains of a burning feeling in the part affected. J. S. Fraser.

\section{Gərber (Konigsberg).--The Effect of Salvarsan on Syphilis of the Upper Air-passages, Scleroma, Plaut-Vincent's Angina, and Scurvy. "Arch. f. Laryngol.," vol. xxiv, Part II.}

In the author's earlier cases the drug was given by Wechselmann's intra-muscular method, in the later by Schreiber's intra-venous method. Comparing the two, he considers the intra-venous the more disagreeable at the time, but the less so afterwards. In two cases of intra-venous injection collapse occurred, and in five out of nine cases shivering, vomiting, and diarrhoe:. He, however, regards the drug as absolutely harmless if properly used. Of the twelve syphilitic cases, the most remarkable was one of laryngeal stenosis, which had for three years resisted treatment by mercury and iodides and dilation with bougies. Four days after the injection all respiratory obstruction vanished, and the glottis became quite normal in appearance. In eleven of the twelve syphilitic cases all signs of the disease were absent in from three to fourteen days after the injection, while in the twelfth (a nasal case with sequestrum), healing was complete in six weeks. 'The two cases of Vincent's angina and the one 
case of scurvy were healed in from three to five days after injection. The case of scleroma remained unaffected.

'The author regards salvarsan as the best and most rapid remedy for diseases due to spirochætes, especially, of course, syphilis.

\section{Thomas Guthrie.}

Bunch, J. L.-Case of Congenital Syphilis Treated by "606." " Proc. Roy. Soc. Med.," May, 1911 (Section for the Study of Disease in Children.)

At the age of three weeks the child suffered from rhinitis, which developed into "smuftles": later a papular eruption and mucons tubercles developed. Salvarsan $(0.04 \mathrm{grm}$.) was injected in the scapular region; this was followed by a rise of temperature and local swelling. A fortnight after the injection the mucous tubercles and snuffles had disappeared, but the Wassermann reaction was still positive ten days later.

J. S. Firaser.

\section{REVIEWS.}

The Deaf Child: A Mamual for Teachers and School Doctors. By James Kerr Love, M.D. Bristol: John Wright \& Sons, Ltel. London: Simpkin, Marshall, Hamilton, Kent \& Co., Ltd., 1911.

The present reviewer casually opened this work with a view to skimming over a few pages before passing it on to a more capable analyst. He found himself so attracted that he read every page with the greatest interest, profit, and pleasure. Dr. Kerr Love produces many facts and figures, and from them elaborates certain principles which camnot fail to appeal to every reader. His main contention is that too much consideration has always been given to the "system," whether oral, manual, or sign, and too little to the "deaf child" as such. He takes up a judicial position, and looks fairly at the defects and failures as well as at the excellencies and the triumphs of each system. The oral system is, of course, the ideal one, and it is not surprising that it should have inspired an enthusiasm leading to more zeal than discretion in its use. Unfortunately it has its limitations, and Dr. Kerr Love, while one of the keenest of its supporters, indicates where these are to be reached. All interested in the "deaf child" must read this informing work.

D. $G$.

Handbuch der Speziellen Chirurgie des Ohres und der oberen Lnftwege. Herausgegeben von Drs. L. Katz, H. H. Preysing, and F. BlumenFELD. Wïrzburg: Curt Kabitzsch, 1911.

We have received for review part of the first volume of this large work which is in the process of publication. Parts $I-V$ of volume $i$ are before us and it is evident from the table of contents that a very comprehensive account of the anatomy and surgery of the ear and the upper air-passages is promised us. The names of Katz, Preysing and Blumenfeld are a suffieient guarantee that the work will be carefully edited.

Parts I and II furnish a descriptive account of the topographical anatomy of the head, exclusive of the nasal cavities and the ear, and is from the pen of J. Sobotta, Professor of Anatomy in Wiirzburg. It is undoubtedly of advantage to the surgeon in this field to-day to be able to refer to anatomical points in comnection with the brain and the cranial 